TE YODE OF OPEBATING IN CA8ES OP GANGRENE : NRCEBBITY OF DIAQYOSIS OF IDIOPATHIC AND THAUMATIC GAYGRENE: DIFFEREYCES OF MILITARY AXD CIVIL SURGERT.

In the London Hospital, there has been a case, during the last four weeks, of very considerable practical importanco-a case of amputation of the thigh during the progress of traumatic gangrene. Instances of this disease are happily not of frequent occurrence in civil practice; yet Mr. WORDsW ORTH, who had charge of the patient (with Mr. LoKE), from what he had seen in military practice of similar injuries from cannon shot in the Crimea, deemed it advisable to amputate. The case has recovered most satisfactorily, to the surprise of everybody. We need not say that, as a common rule in gangrene, surgcons are in the habit of waiting for the " red line of separation" to form; and, only a very few years ago, it was held that this was the mode in which mortification was invariably arrested by Nature; and amputation, accordingly, was as invariably deferred. One sees this maxim still observed in Guy's and many hospitals where the gangrene proceeds from constitutional or internal causes.

We owe the improvement of amputating, as regards traumatic gangrene, to the military surgeons, and more especially to Baron Larrey. The wisdom of the rule of not amputating is acknowledged in mortifications from internal causes, such as diseased arteries; but if the maxim were extended to some traumatic examples, "the patients", says a recent writer, "would certainly go to their doom without having what may be called a fair chance of being saved; they would die before the mortification had stopped, or they would sink into a state in which the performance of amputation would be altogether hopeless." In traumatic gangrene, in a word, the experience of the London Hospital, where some of the most appalling traumatic injuries are met with, is very much in favour of the view adopted by Mr. Wordsivorth and the army surgeons : it is dangerous, in fact, to wait for the mortification to stop, or for the red line to appear, because the patient will then die of the extension of the disease, and of its effects upon the constitution, before such appearance presents itself as may be supposed to sanction the operation.

It was urged, however, in the present case, that gangrene would seize the stump after the amputation; but we have seldom or never seen in such a patient a more healthy stump, or one more quickly healed, though the operation was followed by very severe and alarming secondary hæmorrhage. In those occasional cases of popliteal aneurism where the latter bursts, giving rise to mortification, an operation like the present may safely be recommended, as well as in those horrible accidents where painters or glaziers fall through a skylight, cutting and breaking their arms, followed by gangrene. It seems, in fact, almost equivalent to losing a life, not to amputate in such cases on the spot. In fact, in many accidental injuries, the truest conservatism is to save the life at all hazards by amputation, and thus provent mortification having time to set in by a proper primary operation, apparently, but only apparently, so formidable.

In gangrena senilis, according to Syme, good results are arrived at by morphia in large doses, good milk diet, and linseed poultices to the affected part.

The following is an outline of Mr. Wordsworth's case.

Robert F., aged 40, a strong looking agricultural labourer, was admitted into the London Hospital September 2nd, with severe compound fracture of the leg, going rapidly into gangrene. He stated that he was riding on his cart or wagon, and was knocked with immense force against something like a turnpike gate; he was so stunned he did not remember very well how it occurred. The limb was terribly smashed, and went from bad to worse, till, several days efter, on gangrene making its appearance, his life was despaired of.

Bept. 15th. Though some rariety of opinions occurred, Mr. Wordsworth to-day, during the spread of the gangrene, resolved to amputate, which he did after the patient was placed under the effects of chloroform.

Bept. 16th. The patient had half a grain of opium every three hours.

Sept. 22nd. The operation has been done a week, and, with the exception of very severe secondary hrmorrhage, he is going on well. The stump is most healthy.

Oct. 9th. He seems quite recovered.

\section{OHitginal Commminations.}

\section{OV.ARIAN DISEASE AND GELATINIFORM CANCER.}

By James Sentox Syrti, Esq., Liverpool.

SEVERAI instances of the above, conjointly or distinct, having recently come under my notice, I transcribe a few from my note-book for publication in the JourNaL.

CASE I. Sarah Davidson, aged 58, consulted me early in 1855 for abdominal enlargement. She was a widow, of middle hcight, sallow complexion, and much reduced. She stated that her catamenia appeared at 15 , and ceased at 45 . She married at 24 ; had borne four children, and made good recoveries. She said that she had gone out one very damp night in December 1852, lightly underclothed; she felt the cold pass up her body, and experienced severc lancinating pain next morning in the left groin. It was temporarily relieved by sinapisms and rest, but frequently recurred during 1853 , towards the close of which year a lump, of the size of an orange, was obscrved at the seat of pain, tender to the touch, and rery moreable. An operative surgeon urged its immediate removal about this time; she was, however, prevented from acceding to this by family distress-her last child being on his deathbed in consumption, the others having succumbed to the same disease.

When she came under my care, her size was enormous. The abdomen was spherical and streaked with distended veins; fluctuation was perceptible in parts, and indurated protuberances (colloid) very distinct and sensitive. There was retroversion of the uterus. The skin was very dry; the tongue clean and red; the pulse 94 , and small. The treatment consisted chiefly of cod-liver oil, with quinine, iodine, and mercurial embrocations, with warmth and support to the tumour, attention to the secretions, and generous diet. In October 1855, nocturnal perspiration set in. The swelling had increased, and fluctuation was well marked. I advised operation, and proceeded to perform it - using Simpson's exploring needle (a course all should pursue), before introducing the larger trocar, two inches to the left, and below the umbilicus. Six quarts of black coffee-looking fluid were withdrawn. Turpentine was injected, and applied externally with compression. The patient bore the operation well ; she passed a restless night, and romited next morning a quart of fluid similar to that removed on the previous day. Small doses of calomel and opium were given for a few days; and, when the ferer had subsided, bromide of potassium in vegetable tonics. Her recovery was rapid. She has had no return of swelling or pains, and can undergo any exertion without fatigue.

CASE II. In July $185 j$, I was requested to visit the lady of Col. ㄴ. aged 38, above the average height, of strunous habit, and delicate form. She had been married aix years, but had had no family. Menstruation was painful, but had been regular since the age of 13. She complained of a swelling in the left iliac region, attended with frequent darting pain, provoked by sudden movement, uninfluenced by position, and unrelieved by rest. On examining the abdomen, a tumour, not unlike an oil-flask in shape and rize, was felt florting in the region affected, falling towards the right with a corresponding motion of the body. The neck of the uterus was unnaturally elongated; the os was thiek: 
ened, and the fundus retroverted. The skin was very dry; the pulse weak. She stated that she suffered, since a girl, every autumn, from boils; these were of a formidable character when in India, from which country she returned in August 1854, after five years residence. For two years, she had had each morning, at five o'clock, violent retching and vomiting of matter like the white of eggs, less copious at the menstrual period. In April 1855, she was on a visit to the North-at which time the weather was excessirely cold, and she was lightly and carelessly habited. She was aroused from sleep on the night of April 13th, with excruciating pain in the left groin, of several minutes duration. Neither redness nor swelling was discernible next morning, nor had she any inconvenience in walking. On the right of May 18th, the pain returned, lasted an hour, and cxtended to lumbar region of the same side. A lump, of the size of an apple, fixed and tender, occupied the sent of pain on the next day. A swelling, similar, but slower in its progress, appeared a fortnight afterwards in the right iliac region. Both tumours increased until June 1st, when profuse purulent diarrhoea came on, with the result of leaving no swelling on the right, and reducing that of the left very considerably. After she came under my care, this diarrhoea rarely occurred; and the left tumour enlarged so rapidly that its weight became a source of annoyance, to obviate which an elastic support was worn till Sept. 14th, when something was felt to give way internally, and violent peritoneal inflammation set in. Leeches, mercurials, and diaphoretics reduced the peritonitis; but its decline was followed in a fortnight (the exact time between the formation of each attack in May) by a return of the swelling on the right side, which ran a similar course. It should have been stated that iodide of potassium was employed previous to the first attack; this was again prescribed, with camphorated oil as a liniment. The albuminous vomiting before referred to, continued; and, when distressing, was alleviated by creasote in lime-juice. In September, the swelling was at its height; fluctuation was distinct, and some spleen-like nodules, painful under manipulation, were perceived. To these, iodine ointment, with camphorated oil, was freely applied. Oil of turpentine was given internally. The urine, which was scanty, bccame porter coloured and copious. I had, about this time, the pleasure and privilege of consulting with Professor Simpson-our highest authority on these matters. Bromide of potassium was, at his suggestion, substituted for the iodide; and the appetite and flesh certainly increased under its use. The abdominal enlargement, which had been decreasing for some time before, continued to diminish; and, in April last, this lady went out to India, reduced two-thirds in size, free of pain, and with scarce a trace of the glandular protuberances over the abdomen. In a letter just received from her, she says that some slight increase in the swelling - consequent on the voyage-is the only complaint.

Case IIr. Mrs. Dalston was first seen by me in February 1856 , in consultation with Mr. Hamilton, her medical attendant. The patient's age was 38 , her complexion fair; she was cachectic and emaciated. The menses disappeared a year previously. She had been married thirteen years, and had borne two living children; had had one miscarriage, and had been instrumentally delivered of a dead fœtus, followed by alarming hæmorrhage. This occurred nearly four years ago; and her health then began to decline. Overfatigue and cold were the assignable causes for a swelling that appeared about this time in the left groin, from which lancinating pain extended to the lumbar region. The urine was very scanty, and diarrhcea was frequent. Opiates were prescribed, but had soon to be discontinued, owing to dyspeptic symptoms and greenish watery vomiting, from which she suffered severely throughout her illness. Early in 1855, a lump was observed in the right iliac region; it was ushered in with fever, and was treated antiphlogistically as before. From this time, the abdomen became uniformly enlarged. Belladonna plaster and bandaging were omployed without any relief. Stimulants were used, and generous food. The swelling, how- ever, increased rery rapidly, and was so compressible that tapjing wass resorted to at the end of the year; but no fluid came. My opinion coincided with that of Dr. Hamilton and others, that it was double orarian dropsy, with multilocular cysts and colloid complication-large nodules, hard, fixed, and painful, being present. Fluctuation appeared so erident under manipulation, that we prevailed on Mrs. D. to submit again to operation. We used, in this instance, Simpson's exploring needle, and punctured in two places, without eliciting any fluid. The wounds were closed, and our patient, after a few weeks, sank of inanition on May 6th. No pulmonary or cardiac affection was olserved in life.

Post Mortex Exinivatrox, made on May.7th. Surgeon Wade, of H.M.S. Geyser, assisted us. The abdomen measured between four and five feet in circumference, and between three and four feet anteriorly and longitudinally. Our first incision brought us upon a thick layer of fat, which occupied the place of muscle, and immediately underneath a mass of mottled grey colour camo into view. The peritoneal covering was easily detached in front, with difficulty behind. The colon was firmly adherent, throughout its course, to the tumour, which, stripped of its outer covering, appeared to consist of homogeneous, glistening, agglutinated nodules, varying but little in size and noue in shape: each was convex anteriorly, slanting towards its periphery, and separated with difficulty from its fibrous partition. An incision, six inches deep, carried the knife through this gelatinous structure into fluid, of which there were nearly two gallons, of urinelike character. The walls of the eyst were internally pultaceous and gangrenous, and emitted an awfully offensive odour. On removing the tumour, which weighed upwards of eighty pounds, the intestines appeared in a diminutive coil, and had a yellowish colour. The spleen was of thrice its natural size, and congested. The bladder was filled with a green caseous scmicartilaginous substance; and its walls were friable and crackling, from its limy or chalky transformation. The uterus was atrophied, and barcly admitted the smallest probe in its cavity. The ovaries were natural. The right bidney was hypertrophied; the left was wanting. The pelvis of the latter was, however, subsequently traced in the tumour, with which its structure had become perfectly identified. The liver was of a gold colour, and much atrophied.

CAse Iv. Mrs. $\mathrm{P} \longrightarrow$, aged 38 , requested my attendance in September 1855 , in reference to a pain and swelling that had appeared above the right groin, induced by cold. She was of middle height and strumous habit. She stated that, nine years ago, she had inflammation of the spine, and, in her twenty-third year, a lump in the left side, correspouding in all respects with the one under notice : it was of about the size of a large cup, very moveable, and had disappeared suddenly after two mouths. She had, from a girl, been subject to severe lancinating pains through the abdomen, irrespective of her menstrual period, and only relieved by watery vomiting, which her friends frequently induced by striking her between the shoulders. She had always been regular, and her secretions had been natural. She was under my care three months. The inflammation was soon subdued; but the swelling remained, and, in the course of five weeks, became general over the abdomen: fluctuation was partial. Three of four points of induration, painful on pressure, and otherwise resembling those specified in previous cases, were very distinct. There was also watery romiting, with loss of strength and appetite. Gentle mercurial friction was ordered; all pres. sure was avoided; bromide of potassium was given internally; generous diet, attention to the bowels, etc., were enjoined. This lady became pregnant in November, and was delivered of a healthy male child in July last. The glandular protuberances continued during gestation, but have since disappeared : the presence of fluid may still be detected; but she can undergo any fatigue without muffering, and professes herself hearty and well.

Case v. Lydia Powel presented herself in March 185.4. 
Her age was 31, her complexion dark : she was much emaciated; unmarried. She said that, in 1851-52, she suffered severely from gnawing pain in the left iliac and lumbar regions, accompanied by uncomfortable tightness round the waist, and frequent watery romiting. She was able, however, to follow her duties as housemaid until October 1853 , when she was laid up with inflammation in the right side, of which there was a recurrence in December. After the latter, the abdominal enlargement became general; and, when examined by me, appeared hard, spongy to the touch, without fluctuation, and streaked with distended veins. Her debility was rery great; her appetite inconstant; the menses regular; the urine scanty; the tongue red; and the pulse small. There was considerable anteflexion of the womb. Iodide of potassium, alternately with tincture of muriate of iron, in infusion of calumba, were prescribed; plaster of mercury with ammoniacum was applied over the tumour, and an opiate was given to relieve the pain. In April 1855, she had an attack of peritoneal inflammation, which was ushered in by the loss of nearly two quarts of blood per vaginam. This illness confined her to her room for ten weeks. The tumour went on increasing ; and, towards the close of the year, although it retained its spongy character and no fluid could be detected by percussion, I proposed to use the exploring needle : but to this she objected, and absented herself till July 1856. Fluctuation was eren then indistinct; but her life was so miserable that submission to any measure, calculated to give relief, was cheerfully complied with; certainly her haggard look and cmaciated frame held out little encouragement to either.

August 15th. The patient, reclining on her left side, was operated on, as in Case 1. Five gallons and a half of dark coffee-like thick fluid were withdrawn. An ounce and a half of oil of turpentine, with half an ounce of tincture of iodine, were injected, and the trocar was corked; and wine and beef-tea were ordered.

August 16th. She passed a restless night; the urine was more abundant, and dark. The watery romiting continued. The abdomen was painful on pressure; the tongue red; the pulse 140 . Three quarts of tar-like matter were with difficulty pressed out. Turpentine and iodine were again injected, and the trocar was withdrawn. A sinapism was applied to the epigastrium for sickness, and calomel and opium were given every four hours.

August 17th. She had a good night. The skin was moist. She felt less pain orer the abdomen; and the sickness was abated. Quinine was substituted for calomel and opium, and ale for the wine. This patient continued to improve steadily. She is gaining flesh, and is able to walk about her room.

REMARKS. There are in these cases many points of interest and resemblance. All were ascribed to cold, commenced with swelling and lancinating pain in the left iliac region, and were attended with dry skin and romiting. Each presented, subsequentily, the rein-streaked abdomen and painful glandular protuberances: whether these were cancerous (colloid) or tubercular, merits inquiry. My impression is, that these, howerer difficult of detection through life, are always present, and are generally of the latter character, in ovarian disease. They may become quiescent, painless, and interfere but little with life, as in four of these patients; or, influenced by temperament, circumstances, etc., may assume a more complex form, as in Case 3, which was, in its way, a pathological museum. Here there was cretifaction, as in tuberculosis, coexisting with cancerous deposit in the bladder; and it is possible, if not probable, that the disease, in this instance, originated in the left kidney, was communicated therefrom to the adjoining glands, and protruded in the region of the left ovary - that organ being unaffected: hence the error and difficuluy of diagnosis. The enormous size and nature of the cyst, and the quantity and character of its contents are also attractive features. The coincidence of age (38) in three is worthy of notice, as well as the romiting, which was a distressing symptom in all. With reference to the trentment, bromide of potassium is decidedly beneficial; bandaging is highly injurious. To assist us, either in diagnosis or operation, Simpson's exploring neodle is indispensable ; and turpentine injection, after emptying the cyst, is well worthy of trial.

\section{REMARKS UPON THAT PORTION OF DR. ROUTH'S PAPER, "ON FACAL FERMENTATION AS}

A SOURCE OF DISEASE", WHICH

REFERS TO CROYDON.

By Alfred Carpenter, M.B.Lond., Croydon.

Dr. RovTH, in his paper read before the Medical Society of London, and published in the present volume of the Association Medical Jodrina, has, at p. 763, fallen into rery considerable errors, where he speaks of the typhoid fever which prevailed at Croydon in the winter of 1852-53. One sentence runs thus:- "The Croydon typhoid ferer, which proved so fatal, was due to water impregnated with drains of a very fotid character." Then again :- "Croy-" don, like most country places, abounds with cessponls." And a little further on the author states, that, towards the end of 1852, the water-supply, which was obtained by steam-power from the chalk, was interfered with in the formation of the new drainage works established by the Board of Health, etc. "The result was a virulent epidemic of typhoid fever."

This is nearly all in the paper that refers to Croydon; and is therefore all that will at this time engage my attention.

Now, fortunately for Croydon, and unfortunately for Dr. Routh's conclusions, they are all erroneous; and were such assertions a sample of the whole paper, that which is really valuable would be worse than worthless.

With regard to the first, the fever did not prove so fatal at Croydon; in fact, its rate of mortality was excessively low, being scarcely more than $2 \frac{1}{2}$ per cent. of the total number of cases. The whole number of deaths from fever during the six months which included the whole period of the epidemic (i.e., from Michaelmas 1852 to Lady-day 1853), was only 69 , out of a population of nearly 25,000 ; and many of these cases occurred in distant parts of the parish. This fact may be easily proved by referring to $\mathbf{M r}$. Westall's mortality tables, which are compiled from the registrar's books; and also to Mr. Grainger's report to the General Board of Health, and published as a blue book in 1853.

Secondly. There is no proof that the water supplied by the Board of Health was impregnated with fetid matter of any kind : but there is every argument and every fact to prove the contrary to be the case. This is the first time I have ever seen it so stated by any writer upon the subject. Sereral analyses of the water have been made by eminent chemists; and all are agreed that the quantity of organic matter in the water is very small-smaller, indeed, than in any water supplied from other sources around London; and that quantity was not greater in 1852-53 than it is at present.

Thirdly. Croydon does not abound in cesspools; there is, comparatively speaking, scarcely a cesspool in the whole town : nearly 2,000 were destroyed before the fever became prevalent; and they are not now allowed, except in places at a distance from the main sewers.

Fourthly. The water supply was not interfered with by the new drainage works of the Local Board of Health. The works for the drainage and those for the water supply were executed about the same period. The new supply could not therefore be interfered with; but the wells and ponds spoken of by Dr. Routh, and from which the inhabitants drew their previous supply of water, were 80. They were rendered even more impure by the operations of the Board-i.e., by breaking up the old imperfect drains, destroying the cesspools, and causing the porous gravel to be soaked with water loaded with decomposing animal matter in solution. The Board supplied pure water, and 